\title{
The Impact of Stock Index Futures on Spot Market Volatility
}

\author{
Yao Yao \\ Hangzhou Institute of Service Engineering, Hangzhou Normal University, Hangzhou, 310012, \\ China \\ email: yyaoexist@163.com
}

Keywords: Stock Index Futures; CSI 300 Index; Market Volatility; ARCH Model

\begin{abstract}
This paper studies the influence of stock index futures transactions on spot market volatility. Based on a modified GARCH model with a dummy variable, with a sample of daily data of CSI 300 index from 2005 to 2015, the empirical study examined the impact of CSI 300 index futures on the stock market volatility. The result indicates that after the launch of the CSI 300 index futures, the stock market volatility increased in the past five years. Policy measures such as improvement of both spot and futures market are necessary to contain the risks.
\end{abstract}

\section{Introduction}

Stock index future is a financial derivative based on a designated stock index, which can be used for risk management or investment. The academic studies on the relation between futures market and spot market generally cover two topics, influence on spot market volatility and price discovery function. The volatility of the market indicates degree of risk and market efficiency. Whether stock index futures trading influence the stock market volatility, the direction and degree of the influence is controversial in different studies.

The introduction of stock index future aims to improve financial market system, strengthen mechanism and increase market efficiency in China. Five years has passed since the official introduction of CSI 300 index futures in April the 16th, 2010, as the first financial futures product in China. Study of its effect on spot market has practical value.

This paper will analyze the effect of CSI 300 index futures on spot market volatility based on GARCH model. It will arrange as follows: section 2 will focus on stock index futures and its effect on stock market; section 3 will give the method and data description; section 4 will illustrate empirical studies results from the model and data; section 5 will give conclusions and some policy implications.

\section{Stock index futures and its effect on spot market}

The relation between stock index futures and spot market volatility is an inconclusive issue in previews studies. Some research indicates that index futures trading decreases the spot market volatility (Kumar, Sarin and Shastri, 1995; Antoniou, Holmes and Priestley, 1998). The over sensitivity of stock index future market indicates market efficiency. The volatility is the result of price discovery function, hence, desirable. The futures market will adjust to balance status instantly, and induce stock market balance through arbitrage activities. Futures market improves the depth of financial market, provides more liquidity, hence, decrease stock market volatility. Empirical study of Bologna and Cavallo (2002) for the Italian stock exchange based on GARCH model indicates that the introduction of index futures reduced stock market volatility. Some research argue that index futures trading will lead to higher degree of spot market volatility (Lockwood and Linn, 1990; Damodaran, 1990; Antonious and Holmes, 1995). The stock index futures market is oversensitive to information. The leverage effect and to-expire-day effect attribute to higher volatility and magnifies risk. Massive speculative activities increase undesirable volatility. The volatility in futures market will transfer to spot market through arbitragers and hedgers. The research of Antonious and Holmes (1995) on FTSE 100 index cash and futures market found that the introduction of index future did increase volatility in cash market. However, the volatility was not 
result of speculations, but reduction of information asymmetries. Some empirical studies support the opinion that spot market volatility does not change because of index futures trading. The findings of Antonious and Koutmos (2004) show that Nikki 225 and Dax index did not change significantly after introduction of index futures.

There are abundant of theoretical and empirical research on this subject. Most research arrive the same result that the futures market has price discovery function. The lead-lag relationship studies indicate that the futures market has absolute advantage over cash market in price discovery. The price in the two markets influences each other. The futures market price can lead the cash market price because of leverage effect and sensitivity to information in futures market. The methods used in lead-lag studies between futures and cash market include unit root test, co-integration test, error correction model, or Granger test.

CSI 300 index is a capitalization-weighted stock market index complied to reflect price of 300 stocks in Shanghai and Shenzhen stock exchanges since 2005. CSI 300 index is chosen to be the underlying asset of index future because of its anti-manipulative ability. The index has high market coverage and dispersed weight of constituent. CSI 300 index future is a future derivative based on CSI 300 index launched by China Financial Futures Exchange. After four years of simulated transaction, the product is officially introduced on April the 16th 2010. As the first financial derivative in China, CSI 300 index future aims to improve the depth of financial market, perfect the financial system and enhance the market efficiency. The index futures provided more liquidity, improve the stock market efficient through price discovery function. It gives investors an instrument to arbitrage or hedging.

\section{Methodology and data description}

Autoregressive Conditional Heteroskedasticity model (ARCH), first introduced by Engle, is usually applied to study volatility clustering problem of financial time series. The basic model $\varepsilon_{\mathrm{t}}$ $\sim \mathrm{ARCH}(\mathrm{q})$ can be expressed as:

$$
\sigma_{\mathrm{t}}^{2}=\alpha_{0}+\alpha_{1} \varepsilon_{\mathrm{t}-1}^{2}+\cdots+\alpha_{\mathrm{q}} \varepsilon_{\mathrm{t}-\mathrm{q}}^{2}
$$

Large value of the order $\mathrm{q}$ in ARCH model will diminish the effectiveness of the model, and increase the difficulty in parametric estimation. A generalized autoregressive conditional heteroskedasticity (GARCH) model is introduced to solve the problem. The GARCH model is similar to autoregressive moving average model (ARMA model), only it is for the error variance.

The basic model $\varepsilon_{\mathrm{t}} \sim \mathrm{GARCH}(\mathrm{p}, \mathrm{q})$ can be expressed as:

$\sigma_{\mathrm{t}}^{2}=\alpha_{0}+\alpha_{1} \varepsilon_{\mathrm{t}-1}^{2}+\cdots+\alpha_{\mathrm{q}} \varepsilon_{\mathrm{t}-\mathrm{q}}^{2}+\theta_{1} \sigma_{\mathrm{t}-1}^{2}+\theta_{2} \sigma_{\mathrm{t}-2}^{2}+\cdots+\theta_{\mathrm{p}} \sigma_{\mathrm{t}-\mathrm{p}}^{2}$

The steps to model the financial series data such like CSI 300 index through the ARCH is as follows. Firstly, a stationary test is needed to carry out. If ADF statistics is under critical value at significant level 1\%, the model is stationary, hence ARCH model is applicable. Secondly, the autoregressive order need to be selected. Thirdly, ARCH-LM test need to carry out to test high order ARCH effect. Then, ARCH model can be estimated. After parametric estimation, the signigicant test of the estimation result is nessary.

GARCH(1,1) model is the most frequently used model for financial time series. In this paper, GARCH(1,1) will be applied to analyze CSI 300 index, and then test whether the data fits the model, and modify the model if necessary. The basic GARCH $(1,1)$ model can be expressed as:

$$
\begin{aligned}
\mathrm{R}_{\mathrm{t}} & =\mathrm{c}+\varepsilon_{\mathrm{t}} \\
\frac{\varepsilon_{\mathrm{t}}}{\varphi_{\mathrm{t}-1}} & \sim \mathrm{N}\left(0, \mathrm{~h}_{\mathrm{t}}\right) \\
\sigma_{\mathrm{t}}^{2} & =\alpha_{0}+\alpha_{1} \varepsilon_{\mathrm{t}-1}^{2}+\beta_{1} \sigma_{\mathrm{t}-1}^{2}
\end{aligned}
$$

In which, $\varepsilon_{\mathrm{t}}$ is random disturbance term; $\Phi_{\mathrm{t}-1}$ is cluster of all useful information at time (t-1); $\sigma_{\mathrm{t}}^{2}$ is conditional variance; $\alpha_{0}$ is a constant term, or average value in the long run; $\alpha_{1}$ and $\beta_{1}$ indicate the influence of the past information on the volatility in the future.

This paper will select daily CSI 300 index data ranging from January the $4^{\text {th }} 2005$ to December the $29^{\text {th }}$ 2015, which is the time period includes five years before and five years after the introduction of CSI 300 index futures. A dummy variable, indicate before or after the introduction 
of CSI 300 index futures, is applied to the variance equation of GARCH $(1,1)$ model. Thus, the total sample can be divided into two sub-samples, before and after April $16^{\text {th }} 2010$, the day of the launch of the CSI 300 index futures. The data in this paper is the continuous daily return, calculated from CSI 300 index settlement prices.

\section{Empirical analysis.}

1. Descriptive statistics

To provide an overview of the total sample, and to determine whether time series analysis is applicable, the statistical characteristics are examined before the application of GARCH model. The results are as follows:

Table 1. Descriptive statistics of CSI 300 index returns

\begin{tabular}{|c|c|c|c|c|c|c|c|}
\hline Mean & Median & Maximum & Minimum & Std. Dev. & Skewness & Kurtosis & Jarque-Bera \\
\hline 0.000503 & 0.001099 & 0.08931 & -0.09695 & 0.018838 & -0.46269 & 6.076493 & 1147.797 \\
\hline
\end{tabular}

From Table 1, the JB statistics, which is significantly higher than critical value, the null hypothesis is rejected. It indicates that the F-statistics may not be applicable in the time series analysis. The lag order is selected by AIC and SI criteria, as well as AC and PAC coefficient, which is consistent with GARCH $(1,1)$ model.

2. Stationary test

Unit root test is applied to the time series of CSI 300 index daily return. ADF method is selected to test whether the time series is stationary and applicable to GARCH model. The result of ADF test is as follows in Table 2.

Table 2 ADF unit root test result

\begin{tabular}{|c|c|c|c|}
\hline ADF statistics & $\mathrm{P}_{-}$ & Significant level & Critical value \\
\hline-49.72565 & 0.0001 & $1 \%$ & -3.43260 \\
\hline & & $5 \%$ & -2.86242 \\
\hline & & $10 \%$ & -2.56728 \\
\hline
\end{tabular}

At the 1\% significant level, the ADF statistics is far lower than the critical value, which indicates the sample rejects the null hypothesis. The time series is stationary, and suitable for GARCH model analysis.

3. Model estimation

To examine the impact of CSI 300 index futures market on stock market volatility, GARCH $(1,1)$ model is modified, with a dummy variable in the variance equation, indicate before or after the introduction of CSI 300 index futures.

The estimate equations are as follows, the mean equation and the variance equation both have good fitness. The estimation results are as follows:

$\mathrm{R}_{\mathrm{t}}=2.31+0.99 \mathrm{R}_{\mathrm{t}-1}+\varepsilon_{\mathrm{t}}$

$\sigma_{\mathrm{t}}^{2}=1.79+0.06 \varepsilon_{\mathrm{t}-1}^{2}+0.93 \sigma_{\mathrm{t}-1}^{2}+4.5 \mathrm{D}_{\mathrm{t}}$

The coefficient of the dummy variable is positive, means that the launch of CSI 300 index futures lead to more stock market volatility, which indicates that the stock index futures market has a negative effect on stock market stability. In general, the model has a high degree of fitness. The $\mathrm{R}$-squared value is high. The model passed the Durbin-Watson test. The z-statistics of all the coefficients are significant on the confidential level of $99 \%$, except for the dummy variable with $90 \%$.

4. Model test

The ARCH-LM test is applied to examine the quality of the estimation equation form GARCH $(1,1)$ model. The LM test result is as follows in Table 4 . The LM statistics is 0.76 , the P value is higher than $5 \%$ confidential level, so the null hypothesis is accepted, which indicate that the residual series has no ARCH effect. The GARCH $(1,1)$ model passed the LM test.

Table 3 ARCH-LM test results

\begin{tabular}{|c|c|c|c|}
\hline F-statistics & 0.762770 & Prob. F(1,2666) & 0.3825 \\
\hline Obs*R-squared & 0.763123 & Prob. Chi-Square(1) & 0.3824 \\
\hline
\end{tabular}




\section{Conclusion}

Stock index future can be used for risk management or investment. Stock index futures trading influences the stock market volatility, the direction and degree of the influence is controversial in different studies. This paper analyzed the effect of CSI 300 index futures on spot market volatility based on GARCH model. With a sample of the daily data of recent ten years, a dummy variable is added to the variance equation of the GARCH $(1,1)$ model. In comparison of five years before and five years after the launch of CSI 300 index futures, the empirical studies result indicates that the futures market transactions increased the volatility in the spot market. As a hedging instrument with protection purposes, the stock futures can be a risk management instrument. However, the spot market volatility can also coincide with the transactions of futures market, which was the case in Korea. Various policy measures are necessary, in order to manage stock market volatility, as well as financial stability, such as the development of the CSI 300 index futures market, the perfection of transaction mechanism of the spot market and futures market system.

\section{Acknowledgement}

In this paper, the research was sponsored by the Nature Science Foundation of Zhejiang Province (Project No. LQ15F020013).

\section{References}

[1] Adnan Kasman, Saadet Kasman, The impact of futures trading on volatility of the underlying asset in the Turkish stock market. Physica A: Statistical Mechanics and its Applications [J], 2008,Vol 387, issue 12, 2837-2848.

[2] Yang Hou, Steven Li. Information transmission between U.S. and China index futures markets: An asymmetric DCC GARCH approach. Economic Modelling [J], Volume 52, Part B, January 2016, 884-897.

[3] Larisa Yarovaya, Janusz Brzeszczyski, Chi Keung Marco Lau. Intra- and inter-regional return and volatility spillovers across emerging and developed markets: Evidence from stock indices and stock index futures. International Review of Financial Analysis [J], Volume 43, January 2016, 96-114.

[4] Martin T. Bohl, Jeanne Diesteldorf, Pierre L. Siklos. The effect of index futures trading on volatility: Three markets for Chinese stocks. China Economic Review [J], Volume 34, July 2015, 207-224.

[5] Zhou Zhou, Huiyan Dong, Shouyang Wang. Intraday Volatility Spillovers between Index Futures and Spot Market: Evidence from China. Procedia Computer Science [J], Volume 31, 2014, 721-730.

[6] Pierluigi Bologna, Laura Cavallo, Does the introduction of stock index futures effectively reduce stock market volatility? Is the 'futures effect' immediate? Evidence from the Italian stock exchange using GARCH. Applied Financial Economics [J], 2002, vol 12, issue 4, 183-192. 